\title{
Money Laundering in British Columbia Casinos
}

\author{
Critical Gambling Studies Blog Entry by Garry Smith
}

Visit an interactive version of this blog at:

https://criticalgamblingstudies.blogspot.com/2019/08/money-laundering-in-british-columbia.html

\section{The Issue}

For the past decade Vancouver casinos have been a haven for loan sharks and money launderers seeking to camouflage and exploit the proceeds of drug trafficking. These activities have made Vancouver casinos a cesspool of financial crime. High rolling Chinese organized crime members were recruited in Macau casinos to gamble in Vancouver. Millions of dollars from illegal drug sales in China were first deposited into illegal Canadian banks, then later retrieved by gang members to gamble in lower mainland British Columbia casinos. Preferring to play baccarat in exclusive VIP rooms with a maximum wager of $\$ 100,000$; win or lose, after cashing out, 'dirty' drug money is converted into 'deodorized' untraceable casino chips. An estimated $\$ 2$ billion in ill-gotten gains was washed through Vancouver gambling outlets (much of it in Richmond's River Rock casino). The Vancouver Sun investigative reporter who uncovered the scandal, estimated that the top ten Chinese VIPs accounted for close to $50 \%$ of all the casino laundered proceeds of crime.

The money laundering scheme was blatant to the extent that Chinese gamblers entered the casino with duffel bags filled with $\$ 20$ bills (the preferred currency of drug dealers) and in some instances accidently spilled cash on the casino floor in plain sight of casino staff and patrons. Even so, casino operators allowed the suspicious VIPs to buy chips without reporting the inordinately high buy-ins to the Financial Transactions and Reports Analysis Centre of Canada (Fin-TRAC), the federal agency that requires a report on casino monetary exchanges exceeding $\$ 10,000$.

\section{How and Why it Happened}

Key regulatory agencies for British Columbia casinos include 1) the British Columbia Lottery Corporation (BCLC), a crown agency which has the dichotomous responsibilities of growing the business of gambling in the province while at the same time ensuring that gambling operations are fair and tightly controlled; 2) The Criminal Code of Canada, the federal authority under which provinces regulate approved legal gambling formats. The enforcement of Criminal Code violations rests with various law enforcement agencies, including city police, the RCMP and provincial government gambling regulators; 3) casino owners operate under provincial license which spells out stringent rules for mitigating on-site criminal activity. Casino oversight was egregiously flawed at the BCLC, casino management and elected official levels. Earlier in the decade the BC government received the highest monetary penalty ever from Fin-TRAC for non-compliance with its money laundering prevention procedures. BCLC regulators and casino management ignored RCMP and local police intelligence concerning the waves of Chinese high rollers frequenting Vancouver casinos and gambling with funds of shadowy origins. Instead of tightening financial crime surveillance in BC gambling venues, the government raised its high roller betting limits from $\$ 5,000$ to $\$ 100,000$ a play. A decision that was justified by claiming that casino revenue maximization is in the public interest. 


\section{The Aftermath}

A changeover in provincial governments resulted in the commissioning of a report on gamblingrelated financial crime. Former RCMP senior executive Peter German produced a 247-page document entitled "Dirty Money: An Independent Review of Money Laundering in Lower Mainland Casinos." The scandal was said to be the result of a total system failure, yet no criminal charges were laid, politicians ousted, or casino licenses suspended. The report resulted only in some recommendations on how casino money laundering can be better regulated. Public reaction to the report was ambivalent, there was a pervasive feeling that culpable actors should be fired and/or indicted and that casino licences should either be suspended or withdrawn. The current Attorney General is pondering a further investigation yet moving at a glacial pace and stating that an inquiry may be too expensive to undertake. ${ }^{1}$ Another concern is that by allowing provinces to conduct and manage their own gambling operations, federal government detachment has contributed to improprieties such as the lack of effective casino oversight in BC.

\section{Lessons to be Learned}

Gambling is known to be a volatile activity that can have a detrimental effect on both individuals and communities if not tightly regulated. The combination of decriminalized and expanded gambling under Canadian provincial government monopolies is ripe for exploitation and corruption. Nearly a half century ago, gambling regulation authority Jerome Skolnick made the following observations (which would seem to be truisms concerning the ethically gray world of commercial gambling and its regulation) in his seminal book House of Cards: The Legalization and Control of Legal Gambling.

When the purpose of legalizing gambling is to raise revenue, a state will face the dilemma of regulating an industry, while at the same time, encouraging it to prosper. This conflict of interest is at the heart of the BC money laundering scandal; to wit, the BC government and casinos have a perverse incentive to look the other way when money laundering occurs. If they curb the activity sizable revenues will be lost.

The larger the economic interest of the state in gambling, the greater is the outside pressure to erode mechanisms of control. In this case, casino industry capture of government regulators paved the way for rampant money laundering.

Classic issues of gambling regulatory law enforcement include the sources of stringency and leniency in the interpretation of rules. In this case, because the BCLC and the casinos were in effect partners, regulators exercised willful blindness in their oversight to the benefit of each party and the detriment of the public good.

\footnotetext{
${ }^{1}$ Since the initial writing of this blog entry, the BC government has announced a wide-ranging investigation into money laundering in the province.
} 